\title{
Nieuwe beeldvormende technieken bij de diagnostiek van het prostaatcarcinoom
}

\author{
Daniela E. Oprea-Lager ${ }^{1}$ Emile F. I. Comans ${ }^{1,2}$
}

Published online: 9 September 2019

(c) The Author(s) 2019

\section{Samenvatting}

In dit artikel worden beeldvormende technieken besproken die worden gebruikt bij de diagnostiek van prostaatkanker en worden toekomstige ontwikkelingen op dit terrein belicht. Nieuwe en op dit moment bij voorkeur gebruikte beeldvormende technieken (prostaatspecifiek membraanantigeen (PSMA), positronemissietomografie met computertomografie (PET/CT) en whole-body magnetic resonance imaging (MRI)) met diffusiegewogen opname, detecteren metastasen die met de traditionele technieken (botscan en computertomografie (CT)) onopgemerkt zouden zijn gebleven. Gegevens over de daadwerkelijk klinische functionaliteit van deze nieuwe technieken ontbreken echter nog. Dit leidt tot praktische dilemma's bij de behandeling van patiënten met prostaatkanker, omdat de resultaten van grote klinische studies zijn gebaseerd op oude beeldvormende technieken. Deze dilemma's kunnen pas worden opgelost als de diagnostische accuratesse van de nieuwe beeldvormende technieken, en de klinische consequenties van vroege detectie van metastasen, bekend zijn.

Trefwoorden beeldvormende technieken $\cdot$ prostaatcarcinoom $\cdot$ metastasen $\cdot$ PSMA $\cdot$ PET

\section{New imaging techniques in the diagnosis of prostate cancer}

\begin{abstract}
In this article imaging techniques are discussed in the diagnosis of prostate cancer and future developments are highlighted. The nowadays preferred new imaging techniques (prostate specific membrane antigen (PSMA) positron emission tomography (PET) and whole body magnetic resonance imaging (MRI)) detect metastases that would have remained unnoticed with traditional techniques (bone scan and computed tomography (CT)). This leads to practical dilemma's in clinical practice, because scientific insights so far are based on the results of studies using old imaging techniques for staging. This dilemma is not solved until the diagnostic accuracy of the new imaging techniques and the consequences of the early detection of metastases are clear.
\end{abstract}

Keywords imaging techniques $\cdot$ prostate cancer $\cdot$ metastases $\cdot$ PSMA $\cdot$ PET

\section{Introductie}

Beeldvorming speelt een belangrijke rol bij de behandeling van patiënten met een prostaatcarcinoom. Voor de initiële

prof. dr. Emile F. I. Comans

efi.comans@amsterdamumc.nl

1 afdeling Radiologie en Nucleaire Geneeskunde, Amsterdam Universitair Medische Centra, locatie VUmc, Amsterdam, Nederland

2 afdeling Radiologie en Nucleaire Geneeskunde, Haaglanden Medisch Centrum, Den Haag, Nederland stadiëring van het carcinoom en voor herstadiëring (biochemisch recidief) zijn verschillende beeldvormende technieken beschikbaar. Daarmee worden locatie en uitbreiding van de ziekteactiviteit geëvalueerd. De laatste jaren zijn de therapeutische opties bij het gemetastaseerd prostaatcarcinoom aanzienlijk uitgebreid. Naast systemische behandeling wordt bij een toenemend aantal patiënten overwogen een lokale behandeling te geven (metastasis-directed therapy) in geval van beperkte metastasering (oligometastasen) of de verdenking op een lokaal recidief in de prostaat na initiële, in opzet curatieve, behandeling (salvagetherapie). Het betreft patiënten met een verhoogd (of oplopend) PSAgehalte in het bloed of lokale symptomen die suggestief zijn 
voor een mogelijk tumorrecidief. Het belangrijkste doel van een dergelijke tailored therapy is systemische behandeling (en de daarbij optredende bijwerkingen) uit te stellen.

Om een nauwkeurige lokale behandeling mogelijk te maken of om betrouwbaar (lokale of systemische) behandeling te kunnen evalueren, worden hoge eisen gesteld aan de betrouwbaarheid van de beeldvormende diagnostiek. Betrouwbare beeldvorming kan mogelijk onnodige morbiditeit van behandelingen vermijden. Het voorkomen van onderbehandeling stelt tegelijkertijd hoge eisen aan de sensitiviteit van de gebruikte diagnostische test(s) [1]. In dit artikel gaan wij in op de verschillende beeldvormende onderzoeken die, in dit verband, een belangrijke rol spelen bij de beslissing een lokale therapie met de patiënt te bespreken.

Bij verdenking op een recidief prostaatcarcinoom worden de traditionele technieken, skeletscintigrafie (botscan) en de diagnostische CT-scan van de thorax en het abdomen/bekken sinds de jaren tachtig van de vorige eeuw vaak als eerste diagnosticum ingezet. Hoewel deze onderzoeken een beperkte waarde hebben voor het aantonen van tumorrecidief en metastasen worden $\mathrm{zij}$, vooral bij hoge prostaatspecifiek antigeen (PSA) waarden, in de meeste richtlijnen nog steeds aanbevolen. Door de intrede van nieuwe beeldvormende technieken met een hogere diagnostische sensitiviteit, zoals positronemissietomografie/computertomografie (PET/CT) en whole body magnetic resonance imaging (MRI) met diffusiegewogen imaging (DWI) worden de botscan en de CT-scan de laatste jaren steeds minder frequent gebruikt [1].

\section{Beeldvorming bij herstadiëring}

\section{CT-scan}

De diagnostische CT-scan geeft anatomische en pathofysiologische informatie door het meten van dichtheid van weefsel en door verschillen in aankleuring na i.v.-contrasttoediening. CT wordt vooral toegepast voor het detecteren van lymfekliermetastasen of orgaanmetastasen bij patiënten met verdenking op een recidief. De gevoeligheid van een diagnostische CT-scan met contrast voor de detectie van lymfekliermetastasen in het bekken en para-aortaal is beperkt. Voor de detectie van skeletmetastasen heeft de CTscan in vergelijking met de botscan eveneens een beperkte waarde. De sensitiviteit van de CT-scan voor de detectie van levermetastasen en longmetastasen is wel hoog; de prevalentie van dergelijke metastasen is echter relatief laag. De toegevoegde waarde van de CT-scan voor de detectie van metastasen bij het prostaatcarcinoom bij verdenking op een recidief is dan ook niet hoog.

\section{Botscan}

Bij een botscan wordt het radiofarmacon (Technetium-99m) gekoppeld aan een bisfosfonaat. $\mathrm{Na}$ intraveneuze toediening zal het gelabelde bisfosfonaat worden opgenomen door actieve osteoblasten. Verhoogde opname op een botscan representeert verhoogde botaanmaak (zoals gezien wordt bij veel benigne en maligne afwijkingen in het skelet). Metastasen in het skelet leiden tot botdestructie. Deze botdestructie leidt tot een toename van osteoblasten- en osteoclastactiviteit en daarmee tot sclerosering respectievelijk osteolyse van het bot, en doorgaans tot een combinatie daarvan.

Bij het prostaatcarcinoom overheerst vaak de osteoblastische reactie van het bot, hetgeen de basis vormt voor de hoge sensitiviteit van de botscan (bij een suboptimale specificiteit). Nadeel van de botscan bij het (her)stadiëren van patiënten met een prostaatcarcinoom zijn, behalve de beperkte specificiteit, het ontbreken van informatie over viscerale en lymfekliermetastasen en ook een lokaal recidief kan niet worden aangetoond. Daarnaast is bij het meten van de respons op therapie bij een ossaal gemetastaseerd prostaatcarcinoom de botscan minder betrouwbaar bij kortdurende toename van de afwijkingen bij een deel van de patiënten met een goede respons (het zogenaamde flairfenomeen).

\section{PSMA-scan}

In de afgelopen jaren is de arena van beeldvormend onderzoek bij prostaatcarcinoom gedomineerd door $\left[{ }^{68} \mathrm{Gallium}\right]$ of [ ${ }^{18}$ Fluor] gelabeld PSMA-PET/CT-imaging. PSMA $\mathrm{PET} / \mathrm{CT}$ is het meest frequent gebruikt in de setting van het biochemische recidief na in opzet curatieve therapie, maar ook, in toenemende mate, bij de initiële stadiëring van patiënten met intermediate en high-riskprostaatcarcinoom.

Een uitgebreid overzicht van de huidige beschikbare PSMA-tracers en hun indicaties in de klinische praktijk is eerder gepresenteerd [2].

PSMA is een type II-transmembraan eiwit, met een hoge expressie in prostaatkankercellen [3, 4]. PSMA-expressie is verhoogd in meer dan $90 \%$ van de primaire tumoren, in lymfekliermetastasen en botmetastasen, zelfs bij zeer lage PSA-waarden [5]. Circa 10\% van de prostaatcarcinomen tonen geen PSMA-expressie en zijn dus PET-negatief en ongeschikt voor (her)stadiëren. PSMA wordt beschreven als een marker van tumoragressiviteit, omdat de expressie van het eiwit correleert met tumorgraad, pathologisch tumorstadium, aneuploïdie en de kans op biochemisch recidief na curatieve therapie [2]. In tegenstelling tot de botscan wordt bij een PSMA-scan dus traceropname van tumorcellen gevisualiseerd (die eerder plaatsvindt dan de osteoblastenrespons in het skelet). Daarnaast is de resolutie van PET 


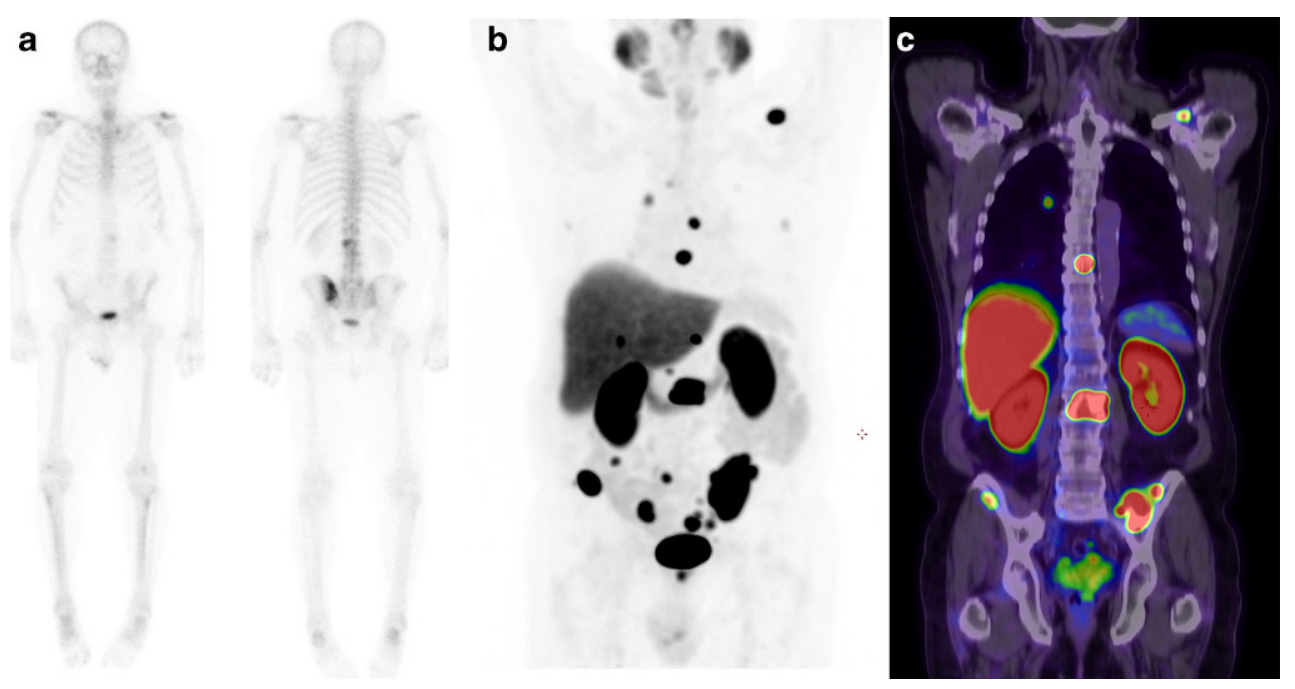

Figuur 1 Scan van een 73-jarige patiënt. In 2017 cT3bNxM0-prostaatcarcinoom, Gleason 5+4=9 bij initieel PSA 24,4 $\mu \mathrm{g} / \mathrm{L}$, waarvoor in opzet curatieve radiotherapie met hormonale therapie gedurende drie jaar. Relevante bevindingen van het aanvullend onderzoek: laboratorium: PSA $0,9 \mu \mathrm{g} / \mathrm{L}$, testosteron $0,2 \mathrm{nmol} / \mathrm{L}$. Botscan: beeld van twee skeletmetastasen in het sacro-iliacaal gewricht links en in de lumbale wervelkolom. ${ }^{18}$ F-DCFPyL PSMA ( 2 weken later): beeld van minimaal 10 ossale laesies verdacht voor metastasen en uitgebreide lymfekliermetastasen in het bekken. a Botscan: total body opnamen van anterior en posterior. b Maximum intensity projection (MIP) PET. c Gefuseerde ${ }^{18}$ F-PSMA PET/CT-beelden

hoger dan die van de botscan (circa $4 \mathrm{~mm}$ bij de PET-scan versus $15 \mathrm{~mm}$ bij de botscan).

PSMA kan gelabeld worden aan $\left[{ }^{68} \mathrm{Ga}\right]$ of $\left[{ }^{18} \mathrm{~F}\right]$ wat resulteert in verscheidene tracers: ${ }^{68} \mathrm{Ga}-\mathrm{PSMA}-11$ (PSMAHBED-CC), ${ }^{68} \mathrm{Ga}$-PSMA-617, ${ }^{68} \mathrm{Ga}$-PSMA I\&T of ${ }^{18} \mathrm{~F}-\mathrm{la}-$ belled PSMA-targeting imaging compounds, zoals ${ }^{18} \mathrm{~F}$-DCFBC (eerste generatie low molecular weight inhibitor of PSMA), ${ }^{18} \mathrm{~F}-\mathrm{DCFPyL}$ (tweede generatie met superieure affiniteit tot weefselbinding) of ${ }^{18} \mathrm{~F}$-PSMA1007 (voordeel: beperkte renale excretie) [6-9]. Met de toenemende schaarste van germaniumgeneratoren (die nodig zijn voor de productie van ${ }^{68} \mathrm{Ga}$ ) wordt verwacht dat ${ }^{18}$ F-gelabelde PSMA-liganden binnen enkele jaren de meest gebruikte tracers zullen zijn.

Op PSMA PET worden metastasen gekenmerkt door intense PSMA-expressie, die hoger is dan de achtergrond en incompatibel met de normale biodistributie van de tracer [10]. Door de fysiologische, intense opname in de lever kunnen eventuele levermetastasen gemist worden [11-13]. Een voorbeeld van een ${ }^{18} \mathrm{~F}$-DCFPyl PET/CT die is verricht bij een patiënt met verdenking op biochemisch recidief prostaatcarcinoom is weergegeven in fig. 1. De discrepantie tussen het aantal verdachte ossale afwijkingen op de botscan en op de PSMA PET/CT-scan die twee weken later is verricht, is evident.

\section{Toekomstige ontwikkelingen}

In de toekomst wordt verwacht dat de beschikbaarheid van whole-body MRI met DWI-sequenties gaat toenemen. Deze techniek biedt de mogelijkheid tot vroege en nauwkeurige detectie van metastasen, met het voordeel van exploratie van een groter veld (whole-body) dan alleen maar de pelviene regio. Bovendien kan MRI vroegtijdig spinale laesies met potentieel risico op het ontwikkelen van neurologische complicaties opsporen. In de setting van biochemisch recidief kan whole-body MRI metastasen opsporen bij zeer lage PSA-waarden (gemiddeld $0.36 \mu \mathrm{g} / \mathrm{L}$ ) [14].

Veel wordt verwacht van radio-guided surgery. Omdat gelabeld PSMA het aantonen van zeer kleine metastasen (circa $2-3 \mathrm{~mm}$ ) bij biochemisch recidief mogelijk maakt, zullen urologen in de toekomst deze tracers intraoperatief kunnen gebruiken voor de detectie van microscopische dan wel atypisch gelokaliseerde metastasen [15]. Dit zal een stimulans zijn voor de ontwikkeling van nieuwe, steeds betere tracers tegen concurrerende prijzen, zeker in het licht van de veranderingen in therapiemanagement die worden verwacht.

De hoge expressie van PSMA op de prostaatkankercellen, maakt het ook mogelijk om gelabeld PSMA voor zowel diagnostische (middels ${ }^{68} \mathrm{Ga}$ of ${ }^{18} \mathrm{~F}$ ) als therapeutische (middels ${ }^{177} \mathrm{Lu}$ of ${ }^{225} \mathrm{Ac}$ ) doeleinden te mogen gebruiken, de zogenoemde theranostische toepasbaarheid [16]. ${ }^{177} \mathrm{Lu}-$ PSMA wordt in studieverband succesvol gebruikt bij de behandeling van patiënten met castratieresistent prostaatcarcinoom. De verwachting is dat de komende jaren de ervaring die is opgedaan met PSMA-theranostics gaat toenemen en de therapieën geïmplementeerd zullen worden in de (inter)nationale richtlijnen. 


\section{Klinische consequenties}

Het is duidelijk dat de nieuwe beeldvormende technieken, met name de PSMA PET-scan, metastasen detecteren die bij de traditionele technieken (botscan) onopgemerkt zouden zijn. Op dit moment zijn er echter nog geen resultaten van grote prospectieve klinische studies over de daadwerkelijk functionaliteit (sensitiviteit, specificiteit, positief voorspelende waarde, negatief voorspelende waarde) van de PSMA PET-scan. Evenmin is duidelijk wat de klinische consequenties zijn van de mogelijk eerder en meer gedetecteerde metastasen. De huidige behandelstrategieën zijn gebaseerd op het aantal metastasen dat is gedetecteerd met de traditionele technieken. Dit betekent een groot dilemma voor de urologische behandelaren in de dagelijkse praktijk. De richtlijnen zijn hierbij evenmin ondersteunend, aangezien de meest geraadpleegde richtlijnen geen eenduidige adviezen geven met betrekking tot de beeldvorming. Wij worden echter geconfronteerd met de dagelijkse praktijk, waarin de trend is dat er steeds meer PSMA PET-scans worden verricht bij de diagnostiek van prostaatkanker. Dit geldt zowel voor de primaire detectie als voor het biochemisch recidief na in opzet curatieve therapie. Een trend die naar ons idee niet meer te stoppen is. Zolang er nog geen gegevens zijn over de werkelijke functionaliteit van de nieuwe beeldvormeden technieken en er nog geen duidelijkheid is wat de klinische consequenties zijn van de extra gedetecteerde metastasen ten opzichte van de traditionele technieken, blijft dit dilemma bestaan. Voor de individuele patiënt dient dit dilemma derhalve in het multidisciplinair overleg (MDO) besproken te worden, zodat daar - op basis van de actuele kennis en gezond verstand - een geïndividualiseerd behandeladvies geformuleerd kan worden. Dat MDO's op basis van gelijke patiëntkarakteristieken met een verschillend advies zullen komen, is onvermijdelijk. De hoop en verwachting is dat er snel wetenschappelijke onderbouwde antwoorden komen die deze dilemma's oplossen.

Open Access This article is distributed under the terms of the Creative Commons Attribution 4.0 International License (http:// creativecommons.org/licenses/by/4.0/), which permits unrestricted use, distribution, and reproduction in any medium, provided you give appropriate credit to the original author(s) and the source, provide a link to the Creative Commons license, and indicate if changes were made.

\section{Literatuur}

1. Lecouvet FE, Oprea-Lager DE, Liu Y, et al. Use of modern imaging methods to facilitate trials of metastasis-directed therapy for oligometastatic disease in prostate cancer: A consensus recommendation from the EORTC Imaging Group. Lancet Oncol. 2018;19(10):e534-e45.

2. Vis AN, Jansen B, Oprea-Lager DE. $\left[{ }^{68} \mathrm{Ga}\right] \mathrm{PSMA}-\mathrm{PET} / \mathrm{CT}$ imaging bij de diagnostiek van prostaatkanker. Tijdschr Urol. 2018;8(1):10-7.

3. Ross JS, Sheehan CE, Fisher HA, et al. Correlation of primary tumor prostate-specific membrane antigen expression with disease recurrence in prostate cancer. Clin Cancer Res. 2003;9:6357-62.

4. Silver DA, Pellicer I, Fair WR, et al. Prostate-specific membrane antigen expression in normal and malignant human tissues. Clin Cancer Res. 1997;3:81-5.

5. Minner S, Wittmer C, Graefen M, et al. High level PSMA expression is associated with early PSA recurrence in surgically treated prostate cancer. Prostate. 2011;71:281-8.

6. Cho SY, Gage KL, Mease RC, et al. Biodistribution, tumor detection, and radiation dosimetry of 18F-DCFBC, a low-molecularweight inhibitor of prostate-specific membrane antigen, in patients with metastatic prostate cancer. J Nucl Med. 2012;53:1883-91.

7. Szabo Z, Mena E, Rowe SP, et al. Initial evaluation of $\left[{ }^{18} \mathrm{~F}\right] \mathrm{DCFPyL}$ for prostate-specific membrane antigen (PSMA)-targeted PET imaging of prostate cancer. Mol Imaging Biol. 2015;17:565-74.

8. Giesel FL, Hadaschik B, Cardinale J, et al. F-18 labelled PSMA1007: biodistribution, radiation dosimetry and histopathological validation of tumor lesions in prostate cancer patients. Eur J Nucl Med Mol Imaging. 2017;44(4):678-88.

9. Wondergem M, Jansen BHE, Zant FM van der, et al. Early lesion detection with 18F-DCFPyL PET/CT in 248 patients with biochemically recurrent prostate cancer. Eur J Nucl Med Mol Imaging. 2019;46(9):1911-8.

10. Jansen BHE, Kramer GM, Cysouw MCF, et al. Healthy tissue uptake of $68 \mathrm{Ga}$-prostate specific membrane antigen (PSMA), 18FDCFPyL, 18F-Fluoromethylcholine (FCH) and 18F-Dihydrotestosterone (FDHT). J Nucl Med. 2019;60(8):1111-7. https://doi.org/ 10.2967/jnumed.118.222505.

11. Laidler P, Dulińska J, Lekka M, et al. Expression of prostate specific membrane antigen in androgen-independent prostate cancer cell line PC-3. Arch Biochem Biophys. 2005;435:1-14.

12. Parimi V, Goyal R, Poropatich K, et al. Neuroendocrine differentiation of prostate cancer: A review. Am J Clin Exp Urol. 2014;2:273-85.

13. Yuan TC, Veeramani S, Lin MF. Neuroendocrine-like prostate cancer cells: Neuroendocrine transdifferentiation of prostate adenocarcinoma cells. Endocr Relat Cancer. 2007;14:531-47.

14. Robertson NL, Sala E, Benz M, et al. Combined whole body and multiparametric prostate magnetic resonance imaging as a 1-step approach to the simultaneous assessment of local recurrence and metastatic disease after radical prostatectomy. J Urol. 2017;198:65-70.

15. Eiber M, Fendler WP, Rowe SP, et al. Prostate-specific membrane antigen ligands for imaging and therapy. J Nucl Med. 2017;58(Suppl 2):67S-76S.

16. Rowe S, Drzezga A, Neumaier B, et al. Prostate-specific membrane antigen-targeted radiohalogenated PET and therapeutic agents for prostate cancer. J Nucl Med. 2016;57:90S-6S.

dr. Daniela E. Oprea-Lager nucleair geneeskundige

prof. dr. Emile F.I. Comans nucleair geneeskundige 